\title{
Ventricular Arrhythmia Risk Based on Ethnicity in COVID-19 Patients on Hydroxychloroquine and Azithromycin Combination: Viewpoint
}

\author{
Sayak Roy ${ }^{1}$ (D) $\cdot$ MainakMukhopadhyay ${ }^{2}$ (D) \\ Accepted: 17 June 2020 / Published online: 27 June 2020 \\ (C) Springer Nature Switzerland AG 2020
}

\begin{abstract}
There are many reports available now, which are mostly observational or registry trial outcomes having varied results on coronavirus 2019 (COVID-19) patients put on hydroxychloroquine and azithromycin combination. Some are showing increased in-hospital mortality and ventricular arrhythmia increase, while some are showing overall benefit with significant viral RNA load reduction. Everyday things are getting more complicated with the publication of these different outcomes. This needs to be addressed.
\end{abstract}

Keywords COVID-19 $\cdot$ Ventricular arrhythmia $\cdot$ Cardiac arrhythmia $\cdot$ Asian $\cdot$ Hydroxychloroquine $\cdot$ Azithromycin

\section{Introduction}

Coronaviruses are positive-stranded RNA viruses which are enveloped and their envelope fused with host cell membrane with the spike glycoprotein (S) mediating the virus entry into cell [1]. There have been reports of efficient in vitro inhibition of Severe Acute Respiratory Syndrome Coronavirus-2 (SARS-CoV-2) with drugs remdesivir (GS-5734) and chloroquine (CQ) phosphate [2]. A recent study by Mehra et al. [3] has shown hydroxychloroquine, hydroxychloroquine with a macrolide, chloroquine, and chloroquine with a macrolide all increased in-hospital mortality as well as de novo ventricular arrhythmia during hospitalization although Asians consisted only $7.9 \%$ of the total study population. In this study, it was interesting to find that the Asian population benefited from the combinations with a hazard ratio and $95 \%$ CI of $0.717(0.668$ 0.769), showing a decrease in in-hospital mortality. Soon after the publication, this study has received a sharp criticism from all over the world regarding their design of sample collection and many other issues [4], and a signed letter was forwarded

This article is part of the Topical Collection on Covid-19

Sayak Roy

sayak.roy.123@gmail.com

1 Consultant Physician, MedicaSuperspeciality Hospital, Kolkata, India

2 Consultant Cardiologist, AMRI Hospitals-Saltlake, Kolkata, India to The Lancet regarding the concerns of the trial [5]. Just after this publication, the UK's RECOVERY trial body [NCT04381936] went back to reassess their interim data of the safety of their ongoing trial drugs, which included HCQ, and found no safety concerns and hence did not stop the trial [6]. Based on the severe criticism, the article was soon retracted [7]. Reports have also shown that the risk is increased with the combination of two separate drugs, each of which can cause drug-induced QT prolongation leading to torsade de pointes (TdP) and subsequent ventricular arrhythmia (VA) [8].

A French study showed a significant benefit when HCQ was used in COVID-19 patients in reducing or even clearing SARS-CoV-2 viral RNA load in 6 days, and the addition of azithromycin reinforced the chances [9]. These conflicting results are creating massive confusion among the medical fraternity. Another retrospective multicenter cohort study involving 1438 hospitalized patients (mostly white) with COVID-19 showed no mortality benefit with the HCQ + AZ combination, but cardiac arrest was significantly higher in the combination group than with each drug alone [10]. Unfortunately, there are rare papers on this combination drug from the Asian subcontinent, and hence other publications are looked for where this combination was used. In a study on uncomplicated falciparum malaria from India, we found a significant improvement in clinical and parasitologic outcomes, combined with cure rates of almost $97 \%$, but at the same time, there were no serious cardiac adverse outcomes [11]. Animal study in an anesthetized guinea pig showed that the combination of AZ with chloroquine did not have any added potential to cause 
arrhythmias [12]. Another study with two groups investigating the pharmacokinetic interaction with the combination of chloroquine and $\mathrm{AZ}$ did not find any clinically significant $\mathrm{PK}$ interaction [13]. It has been often seen that $A Z$ causes cardiac arrhythmias mostly in aged, ill patients with many comorbidities and concomitant medications, which put them intrinsically to high CV risk groups [14]. The chances of prolongation of the QTc (corrected QT) interval and subsequent risk of torsade de pointes (TdP) with HCQ are found to be dose dependant where it is seen that the mean increases in QTc are $6.1 \mathrm{~ms}$ after a dose of $600 \mathrm{mg}$ and $28 \mathrm{~ms}$ after a dose of $1200 \mathrm{mg}$ [15].

\section{Clinical Studies and Cardiac Arrhythmias in COVID-19}

Sudden cardiac death (SCD) is seen in almost 40 cases per 100,000 persons per year in each country of Asia, which is lower than in Europe or the USA, where we find ranges from 50 to 100 per 100,000 persons per year [16]. The commonest fatal cascade in SCD appears to start with ventricular tachycardia (VT) degenerating first to ventricular fibrillation (VF) and later to asystole [16]. In a retrospective cohort study [17] to see the reason of the lower burden of cardiac arrhythmias as compared with Caucasians, it was found that the South Asians had a significantly shorter QRS duration $(p=0.012)$, higher resting heart rate $(p=0.024)$, and a shorter atrioventricular $(p=0.001)$ and ventriculoatrial $(p=0.013)$ effective refractory period. In another study, it was seen that Asians were having less non-valvular atrial fibrillation than Caucasians [18]. There has been a case report in COVID-19 patients showing severe left ventricular dysfunction (ejection fraction of 35\%), diffuse biventricular hypokinesis, especially in the apical segments, diffuse ST segment elevation, and high-sensitivity troponin $\mathrm{T}$ and NT-proBNP levels [19]. In another study from Wuhan, China, it was seen that $26.1 \%$ were transferred to the intensive care unit due to complications, and $44.4 \%$ of them had arrhythmias [20]. Azithromycin was used in $18.1 \%$ and moxifloxacin in $64.4 \%$ of patients in this study. Increased troponin $\mathrm{T}$ levels have also been associated with malignant arrhythmias [21]. A summary of a few trials investigating these two drugs is given in Table 1.

\section{Probable Mechanisms of Cardiac Arrhythmias in COVID-19}

Apart from infarction and heart failure, cardiac arrhythmia in infectious disease is mostly related to myocarditis, proinflammatory effects, and sympathetic overstimulation. Guo et al., 2020 [21] proposed the mechanisms of the myocardial injury with SARS-CoV-2 infection in the form of direct viral infection, causing extensive damage to the myocytes in patients with underlying cardiovascular diseases and indirectly by cytokine storm-mediated systemic inflammatory responses that destabilized coronary plaque and aggravated hypoxia. The cytokine storm seen in severe COVID-19 patients can cause a reduction in coronary blood flow, leading to impaired oxygen supply and subsequent hypoxia-induced myocardial damage as well as microthrombogenesis [21]. In critically ill patients of SARS-CoV-2 infection, thrombotic complications have been reported due to virus-induced endotheliitis [22, 23]. Pan et al. [24] suggested a few probable mechanisms of cardiac arrest in patients during the severe acute respiratory syndrome (SARS) outbreak, and that same concept is now being extrapolated to explain the arrhythmias $n$ SARS-CoV-2. They share the view that (a) SARS-induced lung injury leads to hypoxemia and an altered, imbalanced state in myocardial electricity; (b) direct damage to the new myocardial cells and/or conduction system; (c) aggravation of pre-existing morbidities related to myocardium or conduction disturbances; and (d) endogenous catecholamine release owing to the severe anxiety in the patients that leads to further myocardial electrical instability.

In general, atrial fibrillation is a major predisposing factor to $\mathrm{SCD}$, but in patients without $\mathrm{AF}, \mathrm{SCD}$, and VA, it increase consistently with age [25]. Ventricular fibrillation and ventricular tachycardia are reported in higher proportions with elevated troponin $\mathrm{T}$ levels [26]. The potential role of pharmacological interventions in causing prolongation of corrected QT (QTc) interval must be remembered as these drugs are now quite often used in these frail patients of COVID-19 and include the commonly used drugs hydroxychloroquine, azithromycin, and lopinavir/ritonavir. Antimalarial drugs like hydroxychloroquine have a direct effect on ventricular repolarization by blocking the $\mathrm{KCNH} 2$-encoded $\mathrm{HERG} / \mathrm{K}_{\mathrm{v}} 11.1$ potassium channel and potentially prolonging the QTc [8]. The macrolide azithromycin also shares the same mechanism of blockade of the rapid component, IKr, of the delayed rectifier potassium current IK [27]. The cytokine storm seen in severe COVID-19 patients leads to acute respiratory distress syndrome (ARDS) by releasing many cytokines like interleukin (IL)-1B, IL-6, IL-12 and various chemokines [28], with IL-6, IL-1 modulating the expression and/or function of cardiac $\mathrm{K}+$ and $\mathrm{Ca}++$ channels, thereby causing prolongation of ventricular action potential duration, which finally predisposes to arrhythmias [29]. Tisdale et al. have created a Tisdale risk score for hospitalized patients to predict QTc > $500 \mathrm{msec}$ [30]. This score, nowadays, is in routine use for COVID-19 patients starting HCQ, and it states that a risk score of $\leq 6$ confers low risk, $7-10$ medium risk, and $\geq 11$ high risk of drug-associated QTc prolongation [30]. Druginduced QT prolongation risk is around 6\%, and out of that, $0.3 \%$ have a chance to develop TdP, and VA risk is seen in $2.6 \%$ and the risk to be increased when concomitant multiple QT-prolonging drugs are used [31]. The intensive care unit 


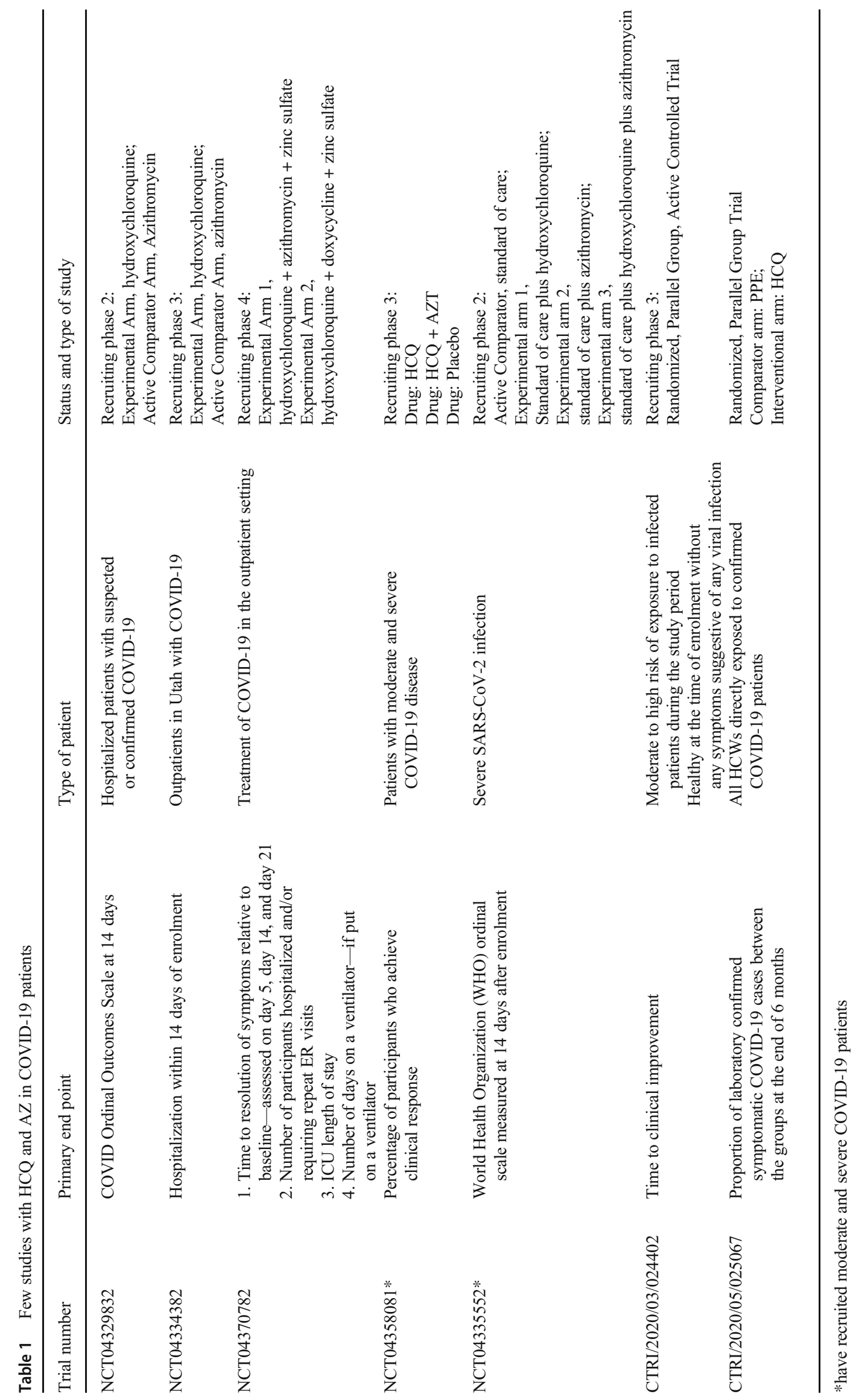


Table 2 Risk factors for development of prolonged QT and torsade de pointes (TdP)

\begin{tabular}{ll}
\hline Non-modifiable risk factors & Female sex; advanced age \\
\hline Metabolic disturbances & Hypokalemia, hypomagnesemia, hypoglycemia, hypocalcemia \\
Existing problems & Cardiomyopathy, bradycardia, recent conversion from atrial fibrillation, \\
& myocardial ischemia, baseline QT prolongation, subclinical long \\
& QT syndrome, ion-channel polymorphism, acute cerebral illness, \\
& hypothyroidism, hypothermia, autonomic dysfunction \\
Antiarrhythmics (amiodarone, sotalol), antibiotics (macrolides, & fluoroquinolones), antimycotics (fluconazole, voriconazole), \\
antiviral drugs (atazanavir), antiemetics (ondansetron, domperidone), & antidepressives (amitriptyline, sertraline), antipsychotics (haloperidol, \\
clozapine), antimalarials (quinine, chloroquine, halofantrine, & quinidine), and others
\end{tabular}

(ICU) of a hospital is dedicated to deal with the sickest of the patients who are already hemodynamically deranged and have multiple existing comorbidities. The QT prolongation with drugs in such a situation seems quite likely. Hence, we often see monitoring of such patients using automatic QT monitoring systems [32]. Some of the risk factors and drugs leading to TdP have been summarized in Table 2 [33].

\section{Asians and Arrhythmias}

Ethnic variations have come to focus after the discrepancies seen in the deaths across many countries [34], and probable reasons for the minorities to suffer more from COVID-19 are increased admission risk for acute respiratory tract infections [35], increased vitamin D deficiency prevalence [36], countryspecific vaccination policies [37], and increased inflammatory markers with high CV risk [38]. Studies have shown that Asians are different in many genetical aspects like the absence of the polymorphic enzyme, CYP2C19, in almost $20 \%$ of the population, which helps in the metabolism of proton pump inhibitors (e.g., pantoprazole, lansoprazole, omeprazole), antidepressants (e.g., amitriptyline, citalopram), antiplatelet drug (clopidogrel), antifungals (e.g., voriconazole), and anticancer drug (e.g., cyclophosphamide) [39]. Higher polymorphisms are seen in gene CYP2D6, which are higher in white Caucasians and, hence, are more predisposed to druginduced prolonged QTc [40]. The frequency of variant $\mathrm{KCNH} 2$ alleles are much more in Caucasians and are much more predisposed to develop drug-induced prolonged QT [41]. Brugada syndrome, an SCN5A (cardiac sodium channel gene)-linked genetic channelopathy predisposing to sudden cardiac death, is nine times and 36 times more common in Asians than Caucasians and Hispanics, respectively [42, 43]. Atrial fibrillation (AF) seems to be lower in incidence in Asians than the Western population [44]. A meta-analysis of 7 prospective randomized clinical trials recruiting 94,785 patients demonstrated that Asians had significantly lower rates of non-valvular AF $(p=0.001)$ as compared with the white population [45]. Hsu JC et al. found that individuals of Asian races commonly have the right anterior accessory pathways [46]. There is also variation in gene expressions related to the long QT syndrome (LQTS), where Asians show KCNQ1 G643S polymorphism in a higher degree than Caucasians [47]. Polymorphisms are often ethnicity specific like HERG P448R and A915V in Asians only [47]. Genes predisposing an individual to drug-induced torsade de pointes are HERGP347S, R784W [48], SCN5A-L1825P, S1102Y [49], etc. A study combining both retrospective approach and prospective approach found $25 \%$ deaths in sudden cardiac deaths (SCD) category in their 5-year retrospective approach and 21 SCD victims in their 2-year prospective approach, out of which arrhythmogenic right ventricular cardiomyopathy constituted $10 \%$, hypertrophic cardiomyopathy shared $5 \%$, and $85 \%$ had negative autopsy [50]. A retrospective case-control study to determine the lower risk of AF in South Asians, involving 60 South Asians and 60 Caucasians, found that the left atrial size was smaller in South Asians as compared with Caucasians with lower left ventricular mass ( $p=0.022)$, all of which might lead to a reduced risk of arrhythmogenic substrate formation (e.g., reentry circuit, fibrosis development) [51]. Another prospective study involving both Caucasians and South Asians found that the South Asians had significantly narrower QRS complex ( $p<0.001$ for males and $p=0.002$ for females), shorter QTc interval ( $p=0.038$, females), lower $\mathrm{P}$ wave dispersion ( $p=0.039$ for males and $p=0.004$ for females), and lower supraventricular ectopic activity ( $p=0.024$ for males, $p=0.004$ for females) [52].

\section{Conclusion}

It is likely that the severe COVID-19 patients are aged, fragile, and hemodynamically unstable with multiple existing comorbidities, and, hence they are prone to develop cardiac arrhythmias of all sorts. From the above facts, we can see that Asians are less susceptible than Caucasians in developing cardiac arrhythmias in general, but the scenario might not be 
applicable in the face of a cytokine storm that goes on in the severe COVID-19 patients. Hence, in these situations, we must maintain extreme cautiousness while prescribing these combination drugs, which can prolong the QT interval. Severe COVID-19 patients should be kept out of these potential arrhythmogenic drug combinations until we get the results from dedicated randomized clinical trials (RCTs). Until that time, we must use HCQ as a prophylactic drug in that population who have a normal baseline QTc or in patients with mild disease and not having any previous myocardial injury or $\mathrm{CV}$ risk factor and should be followed up closely with serial ECGs if needed to see any change after starting the drug. Similarly, AZ use should be restricted to mild COVID-19 infections only until further data is available in critically ill patients from RCTs.

\section{Compliance with Ethical Standards}

Ethical Declaration Not required since it is an analysis of existing literatures without any direct patient participation.

\section{References}

1. Belouzard S, Millet J, Licitra B, Whittaker G. Mechanisms of coronavirus cell entry mediated by the viral spike protein. Viruses. 2012;4(6):1011-33. https://doi.org/10.3390/v4061011.

2. Wang M, Cao R, Zhang L, Yang X, Liu J, Xu M, et al. Remdesivir and chloroquine effectively inhibit the recently emerged novel coronavirus (2019-nCoV) in vitro. Cell Res. 2020;30:269-71.

3. Mehra MR, Desai SS, Ruschitzka F, Patel AN Hydroxychloroquine or chloroquine with or without a macrolide for treatment of COVID-19: a multinational registry analysis. The Lancet [online]. 2020 0(0). Available at: https:/www.thelancet.com/journals/lancet/ article/PIIS0140-6736(20)31180-6/fulltext [Accessed 24 May 2020].

4. The Lancet Editors Expression of concern: hydroxychloroquine or chloroquine with or without a macrolide for treatment of COVID19: a multinational registry analysis. The Lancet [online]. 2020 Available at: https://www.thelancet.com/pdfs/journals/lancet/ PIIS0140-6736(20)31290-3.pdf [Accessed 9 Jun. 2020].

5. Ledford $\mathrm{H}$ Safety fears over hyped drug hydroxychloroquine spark global confusion. Nature. 2020 [online] Available at: https://www. nature.com/articles/d41586-020-01599-9 [Accessed 30 May 2020].

6. www.recoverytrial.net. (n.d.). Welcome - RECOVERY Trial. [online] Available at: https://www.recoverytrial.net/.

7. STAT Lancet. NEJM retract Covid-19 studies that sparked backlash. 2020 [online] Available at: https://www.statnews.com/2020/ 06/04/lancet-retracts-major-covid-19-paper-that-raised-safetyconcerns-about-malaria-drugs/ [Accessed 9 Jun. 2020].

8. Giudicessi JR, Noseworthy PA, Friedman PA, Ackerman MJ. Urgent guidance for navigating and circumventing the QTcprolonging and torsadogenic potential of possible pharmacotherapies for coronavirus disease 19 (COVID-19). Mayo Clin Proc. 2020;95(6):1213-21. https://doi.org/10.1016/j.mayocp.2020.03. 024.

9. Gautret P, Lagier JC, Parola P, et al Hydroxychloroquine and azithromycin as a treatment of COVID-19: results of an openlabel non-randomized clinical trial. International Journal of Antimicrobial Agents. 2020 [online] Available at: https://www. mediterranee-infection.com/wp content/uploads/2020/03/ Hydroxychloroquine final_DOI_IJAA.pdf.

10. Rosenberg ES, Dufort EM, Udo T, Wilberschied LA, Kumar J, Tesoriero J, et al. Association of treatment with hydroxychloroquine or azithromycin with in-hospital mortality in patients with COVID-19 in New York state. JAMA. 2020. https:// doi.org/10.1001/jama.2020.8630.

11. Dunne MW, Singh N, Shukla M, Valecha N, Bhattacharyya PC, Dev V, et al. A multicenter study of azithromycin, alone and in combination with chloroquine, for the treatment of acute uncomplicated Plasmodium falciparum malaria in India. J Infect Dis. 2005;191(10):1582-8. https://doi.org/10.1086/429343.

12. Fossa AA, Wisialowski T, Duncan JN, et al. Azithromycin/ chloroquine combination does not increase cardiac instability despite an increase in monophasic action potential duration in the anesthetized Guinea pig. Am J Trop Med Hyg. 2007;77(5):929 38 PMID: 17984356.

13. Cook JA, Randinitis EJ, Bramson CR, Wesche DL. Lack of a pharmacokinetic interaction between azithromycin and chloroquine. Am J Trop Med Hyg. 2006;74(3):407-12 PMID: 16525098.

14. Maisch NM, Kochupurackal JG, Sin J. Azithromycin and the risk of cardiovascular complications. J Pharm Pract. 2014;27(5):496500. https://doi.org/10.1177/0897190013516503.

15. Mzayek F, Deng H, Mather FJ, Wasilevich EC, Liu H, Hadi CM, et al. Randomized dose-ranging controlled trial of AQ-13, a candidate antimalarial, and chloroquine in healthy volunteers. PLoS Clin Trials. 2007;2:e6. https://doi.org/10.1371/journal.pctr.0020006.

16. Murakoshi N, Aonuma K. Epidemiology of arrhythmias and sudden cardiac death in Asia. Circ J. 2013;77(10):2419-31. https://doi. org/10.1253/circj.cj-13-1129.

17. Neill OJ, Tayebjee MH. Electrophysiological properties of the South Asian heart. Heart Asia. 2018;10(2):e011079. https://doi. org/10.1136/heartasia-2018-011079.

18. Dewland TA, Olgin JE, Vittinghoff E, Marcus GM. Incident atrial fibrillation among Asians, Hispanics, Blacks, and Whites. Circulation. 2013;128(23):2470-7. https://doi.org/10.1161/ CIRCULATIONAHA.113.002449.

19. Inciardi RM, Lupi L, Zaccone G, Italia L, Raffo M, Tomasoni D, et al. Cardiac involvement in a patient with coronavirus disease 2019 (COVID-19). JAMA Cardiol. 2020. https://doi.org/10.1001/ jamacardio.2020.1096.

20. Wang D, Hu B, Hu C, Zhu F, Liu X, Zhang J, et al. Clinical characteristics of 138 hospitalized patients with 2019 novel coronavirus-infected pneumonia in Wuhan, China. JAMA. 2020. Epub 2020/02/08. https://doi.org/10.1001/jama.2020.1585.

21. Guo T, Fan Y, Chen M, Wu X, Zhang L, He T, et al. Cardiovascular implications of fatal outcomes of patients with coronavirus disease 2019 (COVID-19). JAMA Cardiol. 2020. https://doi.org/10.1001/ jamacardio.2020.1017.

22. Varga Z, Flammer AJ, Steiger P, Haberecker M, Andermatt R, Zinkernagel AS, et al. Endothelial cell infection and endotheliitis in COVID-19. Lancet. 2020;395(10234):1417-8. https://doi.org/ 10.1016/S0140-6736(20)30937-5.

23. Klok FA, Kruip MJHA, van der Meer NJM, Arbous MS, Gommers D, Kant KM, et al. Confirmation of the high cumulative incidence of thrombotic complications in critically ill ICU patients with COVID-19: an updated analysis. Thromb Res. 2020;191:148-50. https://doi.org/10.1016/j.thromres.2020.04.041.

24. Pan SF, Zhang HY, Li CS, Wang C. Cardiac arrest in severe acute respiratory syndrome: analysis of 15 cases. Zhonghua Jie $\mathrm{He} \mathrm{He} \mathrm{Hu}$ Xi ZaZhi. 2003;26:602-5 PMID: 14633442.

25. Chao TF, Liu CJ, Tuan TC, Chen SJ, Chen TJ, Lip GYH, et al. Risk and prediction of sudden cardiac death and ventricular arrhythmias for patients with atrial fibrillation - a nationwide cohort study. Sci Rep. 2017;7(1). https://doi.org/10.1038/srep46445. 
26. Driggin E, Madhavan MV, Bikdeli B, et al. Cardiovascular considerations for patients, health care workers, and health systems during the coronavirus disease 2019 (COVID-19) pandemic. J Am Coll Cardiol. 2020; https://doi.org/10.1016/j.jacc.2020.03.031.[epub ahead of print].

27. Lu ZK, Yuan J, Li M, Sutton SS, Rao GA, Jacob S, et al. Cardiac risks associated with antibiotics: azithromycin and levofloxacin. Expert Opin Drug Saf. 2015;14(2):295-303. https://doi.org/10. 1517/14740338.2015.989210.

28. Coperchini F, Chiovato L, Croce L, Magri F, Rotondi M. The cytokine storm in COVID-19: an overview of the involvement of the chemokine/chemokine-receptor system. Cytokine Growth Factor Rev. 2020;53:25-32. https://doi.org/10.1016/j.cytogfr. 2020.05.003.

29. Lazzerini PE, Laghi-Pasini F, Boutjdir M, Capecchi PL. Cardioimmunology of arrhythmias: the role of autoimmune and inflammatory cardiac channelopathies. Nat Rev Immunol. 2019;19:63-4.

30. American College of Cardiology Ventricular arrhythmia risk due to hydroxychloroquine-azithromycin treatment for COVID-19. n.d. [online] Available at: https://www.acc.org/latest-in cardiology/ articles/2020/03/27/14/00/ventricular-arrhythmia-risk-due-tohydroxychloroquine-azithromycin-treatment-for-covid-19

31. Arunachalam K, Lakshmanan S, Maan A, Kumar N, Dominic P. Impact of drug induced long QT syndrome: a systematic review. J Clin Med Res. 2018;10(5):384-90. https://doi.org/10.14740/ jocmr3338w.

32. Drew BJ, Ackerman MJ, Funk M, Gibler WB, Kligfield P, Menon $\mathrm{V}$, et al. Prevention of torsade de pointes in hospital settings: a scientific statement from the American Heart Association and the American College of Cardiology Foundation [published correction appears in circulation. 2010 Aug 24;122(8):e440]. Circulation. 2010;121(8):1047-60. https://doi.org/10.1161/ CIRCULATIONAHA.109.192704.

33. Beitland S, Platou ES, Sunde K. Drug-induced long QT syndrome and fatal arrhythmias in the intensive care unit. Acta Anaesthesiol Scand. 2014;58(3):266-72. https://doi.org/10.1111/aas.12257.

34. Siddique H UK government urged to investigate coronavirus deaths of BAME doctors. The Guardian. 2020 [online]. Available at: https://www.theguardian.com/society/2020/apr/10/uk-coronavirusdeaths-bame-doctors-bma

35. Simpson CR, Steiner MF, Cezard G, Bansal N, Fischbacher C, Douglas A, et al. Ethnic variations in morbidity and mortality from lower respiratory tract infections: a retrospective cohort study. J R Soc Med. 2015;108(10):406-17. https://doi.org/10.1177/ 0141076815588321 .

36. Martineau AR, Jolliffe DA, Hooper RL, et al. Vitamin D supplementation to prevent acute respiratory tract infections: systematic review and meta-analysis of individual participant data. BMJ. 2017;356:i6583. https://doi.org/10.1136/bmj.i6583 pmid: 28202713.

37. Miller A, Reandelar MJ, Fasciglione K, et al. Correlation between universal BCG vaccination policy and reduced morbidity and mortality for COVID-19: an epidemiological study. MedRxiv 2020.03.24.20042937 [Preprint.] 2020. doi:https://doi.org/10. 1101/2020.03.24.20042937

38. Tillin T, Forouhi NG, McKeigue PM, Chaturvedi N, SABRE Study Group. Southall and Brent REvisited: cohort profile of SABRE, a UK population-based comparison of cardiovascular disease and diabetes in people of European, Indian Asian and African Caribbean origins. Int J Epidemiol. 2012;41(1):33-42. https://doi. org/10.1093/ije/dyq175.
39. Flockhart DA, Desta Z, Mahal SK. Selection of drugs to treat gastro-oesophageal reflux disease: the role of drug interactions. Clin Pharmacokinet. 2000;39(4):295-309. https://doi.org/10.2165/ 00003088-200039040-00005.

40. Bernard S, Neville KA, Nguyen AT, Flockhart DA. Interethnic differences in genetic polymorphisms of CYP2D6 in the U.S. population: clinical implications. Oncologist. 2006;11(2):126-35. https://doi.org/10.1634/theoncologist.11-2-126.

41. Shah RR. Drug-induced QT interval prolongation: does ethnicity of the thorough QT study population matter? Br J ClinPharmacol. 2013;75(2):347-58. https://doi.org/10.1111/j.1365-2125.2012. 04415.x.

42. Vutthikraivit W, Rattanawong P, Putthapiban P, Sukhumthammarat W, Vathesatogkit P, Ngarmukos T, et al. Worldwide prevalence of Brugada syndrome: a systematic review and meta-analysis. Acta Cardiol Sin. 2018 May;34(3):267-77. https://doi.org/10.6515/acs.201805_34(3).20180302b.

43. Antzelevitch C. Ion channels and ventricular arrhythmias: cellular and ionic mechanisms underlying the Brugada syndrome. Curr Opin Cardiol. 1999;14(3):274-9. https://doi.org/10.1097/ 00001573-199905000-00013.

44. Chiang CE, Zhang S, Tse HF, Teo WS, Omar R, Sriratanasathavorn C. Atrial fibrillation management in Asia: from the Asian expert forum on atrial fibrillation. Int J Cardiol. 2013;164(1):21-32. https://doi.org/10.1016/j.ijcard.2011.12.033.

45. Novaro GM, Asher CR, Bhatt DL, Moliterno DJ, Harrington RA, Lincoff AM, et al. Meta-analysis comparing reported frequency of atrial fibrillation after acute coronary syndromes in Asians versus whites. Am J Cardiol. 2008;101(4):506-9. https://doi.org/10.1016/ j.amjcard.2007.09.098.

46. Hsu JC, Tanel RE, Lee BK, Scheinman MM, Badhwar N, Lee RJ, et al. Differences in accessory pathway location by sex and race. Heart Rhythm. 2010;7(1):52-6. https://doi.org/10.1016/j.hrthm. 2009.09.023.

47. Modell S, Lehmann M. The long QT syndrome family of cardiac ion channelopathies: a HuGE review. Genet Med. 2006;8:143-55. https://doi.org/10.1097/01.gim.0000204468.85308.86.

48. Yang P, Kanki H, Drolet B, Yang T, Wei J, Viswanathan PC, et al. Allelic variants in long-QT disease genes in patients with drugassociated torsades de pointes. Circulation. 2002;105:1943-8. https://doi.org/10.1161/01.CIR.0000014448.19052.4C.

49. Splawski I, Timothy KW, Tateyama M, Clancy CE, et al. Variant of SCN5A sodium channel implicated in risk of cardiac arrhythmia. Science. 2002;297:1333-6. https://doi.org/10.1126/science. 1073569.

50. Mak CM, Mok NS, Shum HC, et al. Sudden arrhythmia death syndrome in young victims: a five-year retrospective review and two-year prospective molecular autopsy study by next-generation sequencing and clinical evaluation of their first-degree relatives. Hong Kong Med J. 2019;25(1):21-9. https://doi.org/10.12809/ hkmj187256.

51. O'Neill J, Swoboda PP, Plein S, Tayebjee MH. Left atrial size and function in a South Asian population and their potential influence on the risk of atrial fibrillation. Clin Cardiol. 2018;41(10):1379-85. https://doi.org/10.1002/clc.23064.

52. O'Neill J, Bounford K, Anstey A, et al. P wave indices, heart rate variability and anthropometry in a healthy South Asian population. PLoS One. 2019;14(8):e0220662. Published 2019 Aug 23. https:// doi.org/10.1371/journal.pone.0220662.

Publisher's Note Springer Nature remains neutral with regard to jurisdictional claims in published maps and institutional affiliations. 